ГОРОДСКАЯ ОБЩЕОБРАЗОВАТЕЛЬНАЯ ШКОЛА ДАГЕСТАНА

В 20-90-е гг. XX в.

(Публикащия подготовлена в рамках комплексной программы фундаментальных исследований отделения историко-филологических наук РАН «Евразийское наследие и его современные смыслльр». Грант 0209-2015-0001)

М.Я. Мирзабеков,

доктор исторических наук, главный научный сотрудник Института истории, археологии и этнографии Дагестанского научного центра РАН, Махачкала

yash831@mail.ru

Аннотация. Статья посвящена истории и проблемам развития городской общеобразовательной школы Дагестана в 20-90-е гг. XX в. Анализ разнохарактерного архивного материала, данных статистики, переписей населения, работ дагестанских историков по рассматриваемой научно-исследовательской теме позволил воссоздать объективную научную картину развития городской общеобразовательной школы региона за восемь десятилетий истекшего столетия. В работе показано расширение сети, количественные и качественные изменения в составе обучающихся в них учащихся. При этом значительное внимание уделено укреплению материально-технической базы, увеличению численности и качественного состава педагогических кадров в городских общеобразовательных школах республики. В статье охарактеризованы качественные перемены в структуре городской общеобразовательной школы, прослежены закономерности и региональные особенности ее развития в рассматриваемые десятилетия.

Важным вопросом, нашедшим отражение в труде, является введение всеобщего начального, восьмилетнего и среднего обучения подрастающего поколения в дагестанском городе. Автор отмечает причины, экономические и социально-культурные последствия решения социально значимых задач всеобуча в нем. Показана большая работа властных структур республики в этом контексте. В статье нашла отражение и помощь федерального центра в развитии общеобразовательной школы региона, в том числе городской.

Ключевые слова: город, народное образование, культура, общеобразовательная школа, контингент учащихся, всеобщее обучение, учитель, материально-техническая база школ, учебновоспитательный процесс, качество обучения, раздельное обучение мальчиков и девочек, совместное обучение девочек и мальчиков.

\title{
THE MUNICIPAL COMPREHENSIVE SCHOOL IN DAGESTAN IN THE 1920s-1990s
}

\author{
M.Ya. Mirzabekov,
}

Doctor of Historical Sciences, Chief Researcher, Institute of History, Archeology and Ethnography, Dagestan Scientific Center, Russian Academy of Sciences, Makhachkala

yash831@mail.ru

Abstract. The article deals with the history and problems of the development of the municipal comprehensive school in Dagestan in the 1920s - 1990s. Basing on the analysis of various archival materials, statistical data, population census data, works of Dagestan historians on the problem under consideration, the author of the article reconstructs an objective scientific picture of the development of the municipal comprehensive school of the region for eight decades of last century. The article covers the school network expansion, quantitative and qualitative changes in the composition of the students in them. Much attention is paid to strengthening of the material and technical base, increasing the number and quality of teaching staff in municipal comprehensive schools of the republic. The author considers 
qualitative changes in the structure of municipal comprehensive schools of the republic, regularities and regional features of their development within the decades under study.

The important problem, reflected in the article, is the introduction of universal primary, eight-year and secondary education of the rising generation in Dagestan towns. The author analyzes the reasons, economic and socio-cultural consequences of solving of socially significant tasks of universal education in towns and focuses on the great work of the power structures of the republic in this context. The article also covers the assistance of the federal center in the development of comprehensive schools in the region, including the municipal ones.

Keywords: city, public education, culture, general education school, student contingent, general education, teacher, material and technical base of schools, teaching and educational process, quality of education, separate education of boys and girls, co-education of girls and boys.

Октябрьская революция 1917 г. внесла кардинальные перемены в исторические судьбы народов, населявших Российскую империю, определила иное направление экономического, политического, социально-культурного прогресса страны.

В системе мероприятий по развитию культуры стержневым являлось народное образование. Советское государство взялось построить массовую общедоступную школу. 16 октября 1918 г. было опубликовано положение ВЦИК «О единой трудовой школе РСФСР», которая объявлялась массовой, доступной всем детям независимо от социального происхождения и положения, обеспечивающей возможность получения общего образования и трудовых навыков [2].

После установления советской власти в Дагестане в марте 1920 г. в регионе началось создание новых властных структур. В апреле 1920 г. при Дагестанском ревкоме был организован отдел просвещения и печати, который в последующем был преобразован в Народный комиссариат просвещения республики.

Новые органы управления просвещением развернули целенаправленную работу по восстановлению и налаживанию на новых принципах учебных заведений в городах и сельских населенных пунктах региона. На 1 января 1924 г. в Махачкале насчитывалось 11 школ I ступени, где обучалось 2708 учеников, в Дербенте 4 школы со 1032 учащимися, в Буйнакске - 3 школы с 842 учениками, в Кизляре - 5 школ с 535 учащимися, в Хасавюрте - 3 школы с 276 учениками [9, c. 17].

В последующие годы темпы роста школ и контингента учащихся в городах республики возросли. К началу 1927/28 учебного года в городах Дагестана насчитывалось 42 школ, из которых 27 начальных, 11 семилетних, 4 средних с общим контингентом 21,2 тыс. учащихся [15, с. 120].

В 1927/28 учебном году во всех городских и тех сельских школах, где имелись квалифицированные преподаватели, были введены программы Государственного ученого совета $(Г У С)$. Эти программы, наряду с установлением определенного объема знаний и навыков, который учащийся должен был получить в школе, предусматривали связь обучения с общественнополезным трудом, содержали выработанные с учетом накопленного опыта положения о приемах и методах работы в общеобразовательной школе. От действовавших в дагестанских школах до этого программ они отличались более последовательным расположением учебного материала [4, с. 97].

По мере развертывания экономических и социально-культурных преобразований в стране все более настоятельной становилась задача введения начального всеобуча. 25 июля 1930 г. ЦК ВКП(б) принял постановление «О всеобщем обязательном начальном обучении». 14 августа 1930 г. аналогичное постановление приняли ЦИК и СНК СССР. В них предусматривалось повсеместное введение с 1930/31 учебного года всеобщего обязательного обучения детей в возрасте 8, 9, 10 лет в объеме не менее четырехлетнего курса начальной школы и обязательного обучения всех детей в возрасте 11-15 лет, не прошедших первых четырех групп единой трудовой школы. Однако, учитывая трудности бытового и иного характера в отдельных республиках и национальных областях, партия и правительство допускали отступление от указанных сроков на 1 - 2 года [5, с. 473-476].

В республике была развернута большая работа по реализации этой социально значимой цели. По неполным данным, за период с декабря 1931 г. по июнь 1933 г. трудящиеся Дагестана израсходовали на школьное строительство 2 млн. 300 тыс. рублей. В течение 1932 и 1933 гг. в республике было построено 434 школьных здания, что явилось довольно ощутимым вкладом в укрепление материальной базы народного образования $[9$, с.70]. В этом плане многое делалось и за счет бюджетных ассигнований. 
Одновременно властные структуры и органы народного образования региона пристальное внимание уделяли удовлетворению растущих потребностей школы в педагогических кадрах. В 1932 г. в школах Дагестана насчитывалось 4818 учителей, тогда как в предыдущем году 2787 [18, л. 49]. Однако образовательный уровень значительной их части оставлял желать лучшего.

Несмотря на эти и другие трудности и нерешенные проблемы, в 1930/31 учебном году в школы республики было вовлечено 88600 человек, или 98,1\% к плану [7, с. 362]. На 1 января 1932 г. в Дагестане всеобучем было охвачено $80 \%$ детей школьного возраста, в том числе в городах $88,5 \%$ и в сельской местности - 79,2\% [14, с. 240,241$].$

В 1932/33 учебном году дагестанская общеобразовательная школа в основном завершила переход к всеобщему обязательному начальному обучению подрастающего поколения. Из 152000 детей школьного возраста, по данным на ноябрь 1932 г., обучением было охвачено 134000 человек, или $88,2 \%$ [8, с. 81$]$.

Во второй и мирных годах третьей пятилетки (1933-1940) в городах Дагестана быстрыми темпами расширялась сеть неполных и полных средних школ, увеличивался контингент обучающихся в них.

Таблица 1

Городские общеобразовательные школы Дагестана

(без школ рабочей молодежи и школ взрослых на начало учебного года)

\begin{tabular}{|l|l|l|}
\hline & \multicolumn{1}{|c|}{$1937 / 38$ г. } & \multicolumn{1}{c|}{$1940 / 41$ г. } \\
\hline Число школ & 67 & 83 \\
\hline в том числе: начальных & 32 & 61 \\
\hline семилетних & 20 & 26 \\
\hline средних & 15 & 21 \\
\hline прочих & - & 4 \\
\hline В них учителей & 892 & 1076 \\
\hline Численность учащихся - тыс. & 30,8 & 35,1 \\
\hline в том числе: в начальных школах & 6,0 & 3,8 \\
\hline в семилетних школах & 11,6 & 14,1 \\
\hline в средних школах & 13,2 & 16,9 \\
\hline $\begin{array}{l}\text { в прочих школах (вспомогательных для детей с } \\
\text { физическими недостатками) }\end{array}$ & - & $0,3[15$, с. 120$]$ \\
\hline
\end{tabular}

Таким образом, расширение сети городских общеобразовательных школ республики сопровождалось увеличением доли неполных и полных средних школ, контингента учащихся в них. Численность педагогических кадров в городских школах в предвоенные годы увеличилась на 184 человека.

В эти годы властные структуры осуществили ряд мер, напраленных на улучшение качества обучения в школах республики. Важнейшей мерой, призванной улучшить качественный состав учительства, постановку учебно-воспитательного процесса, явилась аттестация педагогических кадров, проведенная в 1936-1938 гг. в соответствии с постановлением СНК и ЦК ВКП(б) от 10 апреля 1936г. «О порядке введения персональных званий учителей и назначении учителей, заведующих и директоров школ». В ходе аттестации общеобразовательная школа освобождалась от лиц, не соответствующих своему назначению. Немалое число педагогов получили рекомендации в кратчайшие сроки повысить квалификацию через сеть заочных отделений высших и средних педагогических учебных заведений $[8$, с. 84].

Существенное влияние на постановку и повышение качества учебно-воспитательного процесса в общеобразовательной школе региона оказал перевод письменности дагестанских народов с арабской на латинскую (1928 г.), а затем (1938 г.) на русскую графическую основу. Эта мера, несмотря на определенные трудности, связанные с переизданием учебников и учебнометодической литературы, переобучением педагогических кадров, утратой дагестанцами традиционных духовных ценностей, обеспечила благоприятные возможности для усиления контактов с народами страны и приобщения их к достижениям русской и мировой культур. 
С введением нового алфавита властные структуры, органы народного образования Дагестана усилили внимание к изучению русского языка в школе. С 1938/39 учебного года преподавание в 5-10 классах школ республики было переведено на русский язык, а родной язык и родная литература сохранялись как учебные предметы. Перевод обучения в 5-10 классах на русский язык, наряду с улучшением преподавания русского языка в начальных классах, способствовал повышению уровня знаний дагестанских школьников, существенно облегчал продолжение ими образования в специальных учебных заведениях. Одновременно эта мера положила начало принижению функциональной роли дагестанских языков в приобщении подрастающего поколения к знаниям, современным духовным ценностям.

Крайне негативно на всех сторонах жизнедеятельности советских людей, в том числе и на развитии общеобразовательной школы, сказалось вероломное нападение фашистской Германии на нашу страну ранним утром 22 июня 1941 г.

За первые два года Великой Отечественной войны (1941-1942) сеть городских общеобразовательных школ в республике сократилась на 7 , а контингент учащихся в них уменьшился на 11,8 тыс. [27, л. 7; 24, л. 140-144].

Многие старшеклассники общеобразовательных школ Дагестана, в том числе и городских, из-за материально-бытовых и иных затруднений вынуждены были бросить школу и начать работу на промышленных предприятиях, в аграрном производстве. Так, на 1 января 1943 г. только в г. Махачкале неохваченным общеобразовательной школой остался 681 ребенок и отсев за учебный год составил 897 человек [19, л. 70].

В 1943 г. с наступлением благоприятных перемен на фронте государственное и партийное руководство страны получило возможность усилить внимание к решению неотложных первоочередных вопросов социально-культурной сферы, в том числе и народного образования. Решением СНК СССР и ЦК ВКП(б) от 11 августа 1943 г. учителям и другим работникам школ была повышена заработная плата $[28$, с. 176]. Отменена плата за обучение в старших классах общеобразовательных школ. В 1943 г. союзным правительством были утверждены «правила для учащихся», которые фиксировали основные права и обязанности учащихся и учителей. Важным документом в плане улучшения деятельности общеобразовательной школы явилось постановление советского правительства от 21 июня 1944 г. «О мероприятиях по улучшению качества обучения в школе». Согласно этому постановлению для учащихся, оканчивающих среднюю школу, устанавливались экзамены на аттестат зрелости. Для учащихся, показавших на выпускных экзаменах особо выдающиеся успехи, устанавливались золотая и серебряная медали. Эти меры способствовали совершенствованию всей деятельности советской общеобразовательной школы.

Проблемы развития народного образования в условиях военного времени были всесторонне проанализированы на VI сессии Верховного Совета ДАССР в апреле 1944 г., на которой был обстоятельно обсужден вопрос «О состоянии всеобщего обязательного обучения в школах ДАССР».

Верховный Совет констатировал, что подготовка школ к началу 1943/44 учебного года в республике прошла намного организованнее по сравнению с предыдущими годами. Из 1160 подлежащих ремонту школ к началу учебного года было отремонтировано 1122 , или 96,7\%. Заготовлено и подвезено в школы 5595 куб. м. дров, или 76,3\% к установленному плану.

Сессия призвала исполкомы местных Советов депутатов трудящихся и органы народного образования «добиться неуклонного выполнения плана по всеобщему обязательному обучению и полного освоения средств, ассигнованных на школьное дело» [8, с. 138-139].

Эти и другие меры директивных и региональных властных структур способствовали преломлению негативных тенденций в развитии городских общеобразовательных школ в республике, расширению сети и увеличению контингента учащихся в них. В 1943 г. число городских школ по сравнению с предыдущим годом в регионе увеличилось на 2 единицы, а обучающихся в них на 3,6 тыс. человек [20, л. 40, 81]. В целом к концу войны сеть общеобразовательных школ в городах республики была полностью восстановлена. В начале 1945/46 учебного года в Дагестане насчитывалось 38 городских общеобразовательных школ Наркомпроса, что на 2 единицы больше по сравнению с началом 1941/42 учебного года [24, л. $140-144 ; 25$, л. $1,22,86,120]$.

Однако к концу войны не удалось восстановить контингент учащихся городских школ региона. К началу 1945/46 учебного года в них обучалось на 2154 человека меньше по сравнению с началом 1941/42 учебного года [24, л. 140-144; 25, л. 1, 22, 86, 120]. 
В послевоенные годы важнейшим направлением социально-культурного строительства в республике оставалось развитие общеобразовательной школы.

С 1949/50 учебного года общеобразовательная школа Дагестана приступила к решению прерванной войной задачи перехода к всеобщему семилетнему обучению подрастающего поколения.

В начале 1950/51 учебного года в городах республики функционировали 107 общеобразовательных школ, из которых 61 начальная, 22 семилетних, 20 средних и 4 прочих (вспомогательных для детей с физическими недостатками). В них работало 1477 учителей и обучалось 40,5 тыс. учащихся [15, с. 120].

В послевоенные годы важнейшей задачей органов народного образования стала задача повышения образовательного уровня работающей молодежи. Для этих целей в городах Дагестана открывались школы рабочей молодежи.

На начало 1949/50 учебного года в школах рабочей молодежи г. Махачкалы обучалось 664 человека, в г. Буйнакске - 162, в г. Каспийске - 270 и т.д. [26, л. 91]. Значительное количество молодых людей повышали свое образование в Республиканской заочной средней школе, имевшей консультационные пункты и филиалы в городах и районных центрах Дагестана.

Параллельно была развернута работа по улучшению учебно-воспитательного процесса в школах республики. Так, в начале 50-х гг. были внесены частичные изменения в учебные планы, обновлены и усовершенствованы программы общеобразовательной школы. Работа эта была проделана Научно-исследовательским институтом школ Министерства просвещения ДАССР с участием ученых Института ИЯЛ Дагестанского филиала АН СССР, Дагестанского госпединститута им. С. Стальского и опытных педагогов-практиков. Использование знаний и опыта широкого круга специалистов позволило повысить уровень издаваемой Дагестанским учебно-педагогическим издательством учебной иметодическойлитературы.

С 1954/55 учебного года во всех городских школах Дагестана было восстановлено совместное обучение детей обоих полов. Как известно, в годы Великой Отечественной войны в областных и краевых центрах, столицах союзных республик и окружных центрах были организованы отдельные мужские и женские школы. В Дагестане раздельное обучение мальчиков и девочек было введено в городах Махачкале, Дербенте и Хасавюрте [4, с. 250, 254, 255].

В целом 50-е годы характеризовались нарастанием позитивных изменений в развитии городской общеобразовательной школы республики.

Таблица 2

Городские общеобразовательные школы Дагестана в 50-е годы (без школ рабочей молодежи и школ взрослых на начало учебного года)

\begin{tabular}{|l|l|l|l|l|l|}
\hline & $1950 / 51$ г. & $1955 / 56$ г. & $1956 / 57$ г. & $197 / 58$ г. & $1958 / 59$ г. \\
\hline Число школ & 107 & 93 & 105 & 106 & 111 \\
\hline в том числе: начальных & 61 & 32 & 40 & 39 & 42 \\
\hline семилетних & 22 & 14 & 13 & 11 & 12 \\
\hline средних & 20 & 45 & 50 & 54 & 55 \\
\hline прочих & 4 & 2 & 2 & 2 & 2 \\
\hline В них учителей & 1477 & 1946 & 2061 & 2184 & 2347 \\
\hline Численность учащихся - тыс. & 40,5 & 40,3 & 41,3 & 42,5 & 45,3 \\
\hline $\begin{array}{l}\text { в том числе: в начальных } \\
\text { школах }\end{array}$ & 8,3 & 2,1 & 2,2 & 2,3 & 2,6 \\
\hline в семилетних школах & 11,7 & 3,9 & 3,7 & 3,0 & 3,9 \\
\hline в средних школах прочих школах & 19,7 & 34,2 & 35,3 & 37,0 & 38,6 \\
\hline $\begin{array}{l}\text { в вспомогательных для детей с } \\
\text { физическими недостатками) }\end{array}$ & 0,8 & 0,1 & 0,1 & 0, & 0,2 \\
\hline
\end{tabular}

Данные таблицы показывают, что 50-е годы характеризовались существенными изменениями в структуре городской общеобразовательной школы республики. Сократилось число начальных 
школ и количество учащихся в них. За десятилетие число городских средних школ в регионе увеличилось с 20 до 55, а обучавшихся в них - с 19,7 тыс. до 38,6 тыс. человек.

С учетом возросших задач экономического и социально-культурного развития страны директивными органами с конца 50-х годов был взят курс на осуществление всеобщего восьмилетнего, а с середины 60-х гг. и среднего обучения подрастающего поколения.

Принятие Верховным Советом СССР в декабре 1958 г. Закона «Об укреплении связи школы с жизнью и о дальнейшем развитии системы народного образования в СССР» привело к значительным изменениям в дагестанской общеобразовательной школе. Неуклонно возрастало количество восьмилетних и средних общеобразовательных школ, укреплялась материальная база, улучшалось трудовое обучение школьников.

К началу 1962/63 учебного года общеобразовательная школа Дагестана успешно решила задачу перехода к всеобщему восьмилетнему образованию. Число восьмилетних школ в республике составило 591, в том числе 46 в городах [16, с. 98]. В отмеченном году в регионе 8 классами было охвачено 95,5\% учащихся, в том числе $96 \%$ выпускников 7 классов [22, л. 7].

Расширение сети восьмилетних школ сопровождалось резким увеличением количества учащихся, обучающихся в них. К началу 1965/66 учебного года в 631 дневной восьмилетней общеобразовательной школе Дагестана обучалось 127,6 тыс. учащихся, или на 52,3 тыс. человек больше по сравнению с началом 1960/61 учебного года [12, с. 205].

Качественно новый этап в повышении образовательного уровня городского населения республики начался с середины шестидесятых годов, когда успехи в развитии народного образования в стране вплотную подвели общеобразовательную школу к решению огромной, социально значимой задачи - переходу к всеобщему среднему образованию подрастающего поколения.

Курс на ускоренное развитие среднего образования и завершение перехода к всеобщему среднему обучению молодежи был намечен XXIII сьездом КПСС (1966 г.). Указания съезда партии были конкретизированы в постановлении ЦК КПСС и Совета Министров СССР от 10 ноября 1966 г. «О мерах дальнейшего улучшения работы средней общеобразовательной школы», в котором были определены практические меры по повышению качества школьного образования [6, с. 139148].

Министерство просвещения ДАССР разработало план перехода ко всеобщему среднему образованию на 1966-1970 гг., в котором в разрезе городов и районов намечалось строительство новых школьных зданий, пристроек к ним с указанием сроков их завершения. Утвержден был также план введения в дагестанской нерусской школе новых учебных планов и программ по русскому и родным языкам.

Вопросы перехода на всеобщее среднее образование молодежи обсуждались на республиканском активе работников просвещения в марте 1967 г., а затем в апреле 1968 г. на съезде учителей республики [4, с. 274].

Такая целенаправленная работа властных структур, педагогической общественности Дагестана была знаменована существенным увеличением числа средних школ и контингента учащихся в них. В 1970/71 учебном году в регионе насчитывалось 377 дневных средних общеобразовательных школ с 233,2 тыс. учащихся, тогда как в 1965/66 учебном году 215 таких школ, в которых обучалось 137,7тыс. человек [12, с. 205].

В 70-е гг. работа по расширению сети средних школ в республике получила дальнейшее развитие. В 1980/81 учебном году в регионе функционировали 660 дневных средних общеобразовательных школ с контингентом 353,7 тыс. человек [10, с. 206]. Значительное их число приходилось на долю городов Дагестана.

Несмотря на эти благоприятные изменения и результаты, в работе общеобразовательных школ республики, в том числе городских, имелось немало недостатков и нерешенных проблем. Не хватало помещений под учебные классы, предметные кабинеты и лаборатории, помещений для проведения внешкольных занятий с учащимися. Во многих школах учебные занятия по-прежнему проводились в две, а то и в три смены. При относительно быстром росте численности детей школьного возраста сотни мальчиков и девочек не были охвачены обучением. Все еще высоким оставался отсев учащихся из школ. К началу 1966/67 учебного года только 46\% обучавшихся своевременно оканчивали восьмые классы. Не выполнялся и план приема окончивших восьмые классы в девятые классы. Руководители некоторых средних и многих восьмилетних школ не имели законченного высшего образования. Так, например, к началу 1967 г. из 297 директоров средних 
школ высшего педагогического образования не имели 15 директоров, а из 564 директоров восьмилетних школ - 124 [4, с. 274-275].

Значительную роль в осуществлении перехода к всеобщему среднему образованию в дагестанском городе играли вечерние и заочные школы.

На промышленных предприятиях республики создавались комиссии в помощь школам. На Буйнакском агрегатном заводе члены комиссии «завод и школа» вели регистрационный журнал, в который регулярно заносились сведения о посещаемости занятий рабочими и служащими завода. Каждый начальник цеха и председатель цехового комитета профсоюза вели по нему учет и контроль за учащимися. При повышении разряда или присвоении новой квалификации учитывался не только факт обучения в школе, но и успеваемость. Естественно, что это стимулировало рабочих не только к посещению школы, но и к получению хороших результатов.

Промышленные предприятия республики приняли участие во Всесоюзном смотре «Каждому молодому труженику - среднее образование», проводившемся в октябре 1972 г.

В рамках подготовки к смотру на заводе стекловолокна было выявлено 120 человек, не имеющих среднего образования. В каждом цехе велась индивидуальная работа, итогом которой явилось то, что $50 \%$ рабочих стали обучаться без отрыва от производства. На заводе был организован консультационный пункт, обеспеченный учебниками и наглядными пособиями за счет предприятия. Для учащихся создали необходимые условия для успешного сочетания учебы с работой на производстве [9, с. 242-243].

В начале 1965/66 учебного года в вечерних школах (включая обучающихся заочно) в городах республики насчитывалось 20,3 тыс. учащихся. К началу 1970/71 учебного года в них обучалось 12,5 тыс. человек [12, с. 204]. В последующие годы численность обучающихся в городских вечерних школах региона продолжала сокращаться, что было обусловлено увеличением притока молодежи с законченным средним образованием на промышленные предприятия.

Параллельно с вечерними школами в реализации курса на всеобщее среднее образование в дагестанском городе все более весомой становилась роль профессионально-технических училищ.

В целом дагестанская общеобразовательная школа к середине 70-х гг. успешно решила задачу перехода к всеобщему среднему обучению подрастающего поколения. В 1973/74 учебном году охват всеми формами получения среднего образования в городах Дагестана достиг 83,3\% [23, л. 5, 6]. В 1975 г. 96\% выпускников 8 классов продолжали учебу в разных формах получения законченного среднего образования [21, л. 108].

В последующие годы городская общеобразовательная школа республики продолжала свое поступательное развитие. Несмотря на снижение рождаемости, урбанизационные процессы в республике обусловили дальнейшее расширение сети городских школ и обучающихся в них. В начале 1985/86 учебного года в Дагестане насчитывалось 153 дневные городские общеобразовательные школы с 136,4 тыс. учащимися, что соответственно на 9 единиц и 17, 2 тыс. человек больше по сравнению с 1975/76 учебным годом [10, с. 204,205; 11,c. 181].

Однако и на этом этапе сохранялись серьезные недостатки в работе педагогических коллективов городских общеобразовательных школ. По данным Министерства просвещения РСФСР, Дагестан в 1982/83 учебном году перевыполнил план по контингентам учащихся (1,9\%), более чем вдвое превышающий средний показатель РСФСР (0,8\%). В Северо-Кавказском регионе республика заняла предпоследнее место (99\% по своевременному выпуску учащихся, продолжающих получать среднее образование $(96,1 \%)$, в то время как в соседних автономных республиках этот показатель составлял 100\%, а средний показатель по РСФСР 99,8\% [9, с. 327].

Большие надежды на улучшение учебно-воспитательного процесса, трудового воспитания и профессиональной ориентации учащихся возлагались на реформу школы, осуществляемую согласно закону «Об основных направлениях реформы общеобразовательной и профессиональной школы», принятому Верховным Советом СССР 12 апреля 1984 г. Верховный Совет ДАССР, обсудив новый закон о школьной реформе, принял постановление «О задачах советских органов республики по реализации реформы общеобразовательной и профессиональной школы».

В постановлении главное внимание уделялось улучшению общеобразовательной и профессиональной подготовки учащихся, повышению престижа учителя, укреплению материальной базы школ, широкому использованию в учебном процессе компьютерной техники, усилению помощи предприятий, организаций, колхозов, совхозов школам республики. Была повышена зарплата учителей, приняты меры поулучшению их подготовки [3,с. 572].

Следует отметить, что в «Основных направлениях реформы общеобразовательной и профессиональной школы» и в постановлениях ЦК КПСС и Совета Министров СССР, принятых в 
развитие реформы школы, уже ни разу не упоминалось об обязательности всеобщего среднего образования, а 27 ноября 1985 г. обязательность среднего образования вовсе была отменена.

В целом в условиях нарастания экономических трудностей школьная реформа 1984 г. не могла достичь сколь-нибудь осязаемых результатов, и вскоре о ней вовсе забыли.

Во второй половине 80-х годов в городах республики с учетом новых веяний в образовательном процессе начали открываться школы и учебные классы с углубленным изучением отдельных учебных дисциплин. В 1986/87 учебном году в Дагестане функционировали 5 профилированных школ: физико-математическая и 4 с углубленным изучением математики, физики, русского языка и литературы [1].

В начале 90-х гг. в городах республики стали открываться первые инновационные общеобразовательные учебные заведения - лицеи и гимназии.

В последнее десятилетие истекшего столетия в городах Дагестана стали открываться и негосударственные общеобразовательные школы. В начале 1999/2000 учебного года в республике имелись 4 негосударственные общеобразовательные школы с 257 учащимися [17,с. 769].

Несмотря на это, основным каналом приобщения подрастающего поколения к знаниям и в новых условиях оставались государственные общеобразовательные учебные заведения.

Резкое сокращение финансирования социально-культурной сферы в стране в 90 -е гг. крайне негативно сказалось на материально-техническом состоянии общеобразовательных школ республики. По данным на начало 1996/97 учебного года, 52,4\% городских дневных общеобразовательных школ Дагестана нуждались в капитальном ремонте, 9,8\% находились в аварийном состоянии, 85,4\% не имели централизованного отопления, $85 \%$ - канализации [13, с. 14].

При всевозрастающих материально-технических трудностях усилиями властных структур и органов народного образования региона удалось сохранить сеть городских общеобразовательных школ и в условиях продолжавшегося роста городского населения обеспечить прирост численности обучающихся в них. Так, в 1990 г. в городах республики насчитывалось 177 общеобразовательных школ, а в 1995 г. - 180. За этот период контингент обучающихся в них увеличился на 9,7 тыс. и в 1995 г. составил 153,5 тыс. человек [13, с. 14].

Ухудшение материального положения, рост безработицы среди молодежи крайне негативно сказались на состоянии вечерних школ в городах. С началом либеральных рыночных реформ властные структуры и органы образования ослабили внимание к этим школам, что привело к сокращению сети вечерних школ и контингента обучающихся в них в городах Дагестана. В начале 1985/86 учебного года в республике насчитывалось 70 вечерних (сменных) общеобразовательных школ, а к началу 1999/2000 учебного года их осталось всего 44. За эти годы численность учащихся в них уменьшилась на 16,8 тыс. и составила в начале 1999/2000 учебного года 11,6 тыс. человек.

Таблица 3

Число городских общеобразовательных школ республики и численность учащихся в них (к началу учебного года, тыс. человек)

\begin{tabular}{|l|l|l|l|}
\hline & \multicolumn{1}{|c|}{1985 г. } & \multicolumn{1}{|c|}{1990 г. } & \multicolumn{1}{|c|}{1996 г. } \\
\hline Число общеобразовательных школ & 1586 & 1588 & 1674 \\
\hline в том числе: в городах и поселках городского типа & 177 & 177 & 178 \\
\hline $\begin{array}{l}\text { Из общего числа школ: дневные общеобразовательные } \\
\text { школы }\end{array}$ & 1516 & 1540 & 1688 \\
\hline в том числе: в городах и поселках городского типа & 153 & 162 & 166 \\
\hline Вечерние (сменные) общеобразовательные школы & 70 & 48 & 47 \\
\hline в том числе: в городах и поселках городского типа & 24 & 15 & 13 \\
\hline Численность учителей & 33,6 & 35,6 & 44,0 \\
\hline Численность учащихся & 425,3 & 413,7 & 454,4 \\
\hline в том числе: в городах и поселках городского типа & 143,8 & 143,8 & 156,8 \\
\hline $\begin{array}{l}\text { Из общей численности учащихся в дневных } \\
\text { общеобразовательных школах }\end{array}$ & 396,9 & 397,9 & 440,3 \\
\hline в том числе: в городах и поселках городского типа & 136,4 & 151,4 & 152,8 \\
\hline В вечерних (сменных) общеобразовательных школах, & 28,4 & 15,8 & 14,0 \\
\hline
\end{tabular}


включая обучающихся заочно

в том числе: в городах и поселках городского типа

7,4

3,9

$[9$, c. $333-334]$

Таким образом, при общем неизменном количестве городских общеобразовательных школ республики сеть дневных школ увеличилась на 13 единиц, а учащихся в них - на 16,4 тыс. человек. За 1985-1996 гг. сеть городских (сменных) общеобразовательных школ в регионе уменьшилась на 11 единиц, а обучающихся в них на 3,5 тыс. человек.

Анализ фактического материала показывает, что в 20-90-е гг. XX в. при целенаправленной помощи федерального центра в дагестанских городах была создана разветвленная сеть общеобразовательных учебных заведений, которые внесли неоценимый вклад в повышение образовательного и культурного уровня горожан республики.

\section{ЛИТЕРАТУРА}

1. Дагестанская правда. 1986, 5 октября.

2. Известия ВЦИК. 1918, 16 октября. C. 609

3. История Дагестана с древнейших времен до наших дней. В 2-х т. Махачкала, 2005. Т. 2.

4. Каймаразов Г.Ш. Образование и наука в Дагестане в XX веке. Махачкала, 2007. - 464 с.

5. КПСС в резолюциях и решениях съездов, конференций и пленумов ЦК. Изд. 8. М., 1970. T.4. $-582 \mathrm{c}$.

6. КПСС в резолюциях и решениях съездов, конференций и пленумов ЦК. Изд. 8. М., 1972. T.9. $-527 \mathrm{c}$.

7. Культурное строительство в Дагестанской АССР. 1918 - 1941 гг. Сб. документов (сост.: Коган Г.Д., Юсупова С.И.). Махачкала, 1980. Т. 1. - 764 с.

8. Мирзабеков М.Я. Культура дагестанского села. XX век: история, проблемы. Махачкала, 1998. $-308 \mathrm{c}$.

9. Мирзабеков М.Я., Ананьева Е.С., Юнаева В.Д. Культура дагестанского города XX в. Махачкала, 2007. - $384 \mathrm{c}$.

10. Народное хозяйство Дагестанской АССР в одиннадцатой пятилетке. Стат. сборник. Махачкала, 1987. - $221 \mathrm{c}$.

11. Народное хозяйство Дагестанской АССР за 60 лет. Юбилейный стат. сборник. Махачкала, 1981. - $190 \mathrm{c}$.

12. Народное хозяйство Дагестанской АССР к 50-летию образования СССР. Юбилейный стат. сборник. Махачкала, 1972. - 222 с.

13. О социально-культурном состоянии в Республике Дагестан. Стат. сборник. Махачкала, 1997. $-58 \mathrm{c}$.

14. Статистико-экономический справочник по ДАССР. Ростов на/Д, 1933. - 280 с.

15. Советский Дагестан за 40 лет. Стат. сборник. Махачкала, 1960. - 168 с.

16. Советский Дагестан за 45 лет. Стат. сборник. Махачкала, 1965. - 122 с.

17. Социальное положение и уровень жизни населения Дагестана. Стат. сборник. Махачкала, 2000. -794 c.

18. Центральный Государственный архив Репсублики Дагестан. (Далее - ЦГА РД). Ф. (Дагестанский обком КПСС). 1п. Оп. 11. Д. 228.

19. ЦГА РД. Ф. 1п. Оп. 23. Д. 1.

20. ЦГА РД. Ф. 1п. Оп. 26. Д. 359.

21. ЦГА РД. Ф. 1п. Оп. 162. Д. 263.

22. ЦГА РД. Ф. (Комитет Республики Дагестан по статистике) р-22. Оп. 25. Д. 109.

23.ЦГА РД. Ф. p-22. Оп. 39. Д. 425.

24. ЦГА РД. Ф. (Министерство образования и науки Республики Дагестан) р-34. Оп. 38. Д. 4.

25. ЦГА РД. Ф. р-34. Оп. 38. Д. 5.

26. ЦГА РД. Ф. (Совет Министров Республики Дагестан) р-168. Оп. 39. Д. 61.

27. ЦГА РД. Ф. (Государственная плановая комиссия при Совете Министров ДАССР) p-260. Оп. 50. Д. 7.

28. Школьное образование в Дагестане. Махачкала, 1968. - 267 с. 


\section{REFERENCES}

1. Dagestan's truth. 1986, 5 October.

2. Izvestiya VTsIK. 1918, October 16.

3. History of Dagestan from ancient times to our days. In 2 tons - 609 with. Makhachkala, 2005. T. 2.

4. Kaimarazov G.Sh. Education and science in Dagestan in the twentieth century. Makhachkala, 2007. $-464 \mathrm{p}$.

5. CPSU in resolutions and decisions of congresses, conferences and plenums of the Central Committee. Ed. 8. M., 1970. T. 4. - 582 p.

6. CPSU in resolutions and decisions of congresses, conferences and plenums of the Central Committee. Ed. 8. M., 1972. T. 9. - 527 p.

7. Cultural construction in the Dagestan ASSR. 1918-1941 gg. Sat. documents (compiled by: Kogan GD, Yusupova SI). Makhachkala, 1980. T. 1. - 764 p.

8. MirzabekovM.Ya. Culture of the Dagestani village. The twentieth century: history, problems. Makhachkala, 1998. - 308 p.

9. MirzabekovM.Ya., Ananyeva E.S., Yunaeva V.D. Culture of the Dagestan city of the twentieth century. Makhachkala, 2007. -384 p.

10. The national economy of the Dagestan ASSR in the eleventh five-year plan. Stat. compilation. Makhachkala, 1987. - $221 \mathrm{p}$.

11. The national economy of the Dagestan ASSR for 60 years. Jubilee stat. compilation. Makhachkala, 1981. - $190 \mathrm{p}$.

12. The national economy of the Dagestan ASSR to the 50th anniversary of the formation of the USSR. Jubilee stat. compilation. Makhachkala, 1972. -222 p.

13. About the socio-cultural status in the Republic of Dagestan. Stat. compilation. Makhachkala, 1997. $-58 \mathrm{p}$.

14. Statistical and economic reference book on DASSR. Rostov on / D, 1933. $-280 \mathrm{p}$.

15. Soviet Dagestan for 40 years. Stat. compilation. Makhachkala, 1960. - 168 p.

16. Soviet Dagestan for 45 years. Stat. compilation. Makhachkala, 1965. - 122 p.

17. Social situation and living standards of the population of Dagestan. Stat. compilation. Makhachkala, 2000. - 794 p.

18. TSGA RD. F. In. Op. 11. D. 228.

19. TSGA RD. F. In. Op. 23. D. 1.

20. TSGA RD. F. In. Op. 26. D. 359.

21. TSGA RD. F. In. Op. 162. D. 263.

22. TSGA RD. F. p-22. Op. 25. D. 109.

23. TSGA RD. F. p-22. Op. 39. D. 425.

24. TSGA RD. F. p-34. Op. 38. D. 4.

25. TSGA RD. F. p-34. Op. 38. D. 5.

26. TSGA RD. F.-168. Op. 39. D. 61.

27. TSGA RD. F. p-260. Op. 50. D. 7.

28. School education in Dagestan. Makhachkala, 1968. - 267 p. 